\title{
Thidiazuron aumenta a produtividade em arroz de terras altas ${ }^{1}$
}

\author{
Cleiton José Alves², Orivaldo Arf', \\ Nayara Fernanda Siviero Garcia ${ }^{2}$, Fernando Shintate Galindo ${ }^{2}$, Arthur Dias Galassi²
}

\begin{abstract}
Thidiazuron increases upland rice yield

The use of plant growth regulators in rice can provide reductions in plant height and decrease plant lodging. This study aimed at verifying the influence of the thidiazuron plant regulator on upland rice in the Brazilian Savannah region. The BRS Esmeralda and IAC 202 cultivars were used, as well as a randomized blocks design, in a 4 × 3 factorial arrangement for each cultivar, consisting of thidiazuron doses $\left(0 \mathrm{~g} \mathrm{ha}^{-1}, 0.3 \mathrm{~g} \mathrm{ha}^{-1}\right.$, $0.6 \mathrm{~g} \mathrm{ha}^{-1}$ and $0.9 \mathrm{~g} \mathrm{ha}^{-1}$ ) and three application times (tillering, floral differentiation and booting), with four replications. The number of spikelets per panicle and spikelet fertility of the BRS Esmeralda cultivar were higher when using the thidiazuron dose of $0.9 \mathrm{~g} \mathrm{ha}^{-1}$ in the tillering stage. The weight of 100 grains of the BRS Esmeralda cultivar fitted a quadratic equation, while the IAC 202 fitted a linear equation, with the best time of application taking place during the tillering stage. For hectoliter weight, the results for the BRS Esmeralda also fitted a quadratic equation, while for the IAC 202 a significant difference was observed only among times, being the booting stage the best application time. Grain yield fitted a positive linear equation for both the BRS Esmeralda and IAC 202 cultivars, with gains of $23.5 \%$ and $6.5 \%$, respectively, when compared to the control. Thidiazuron positively influences grain yield for upland rice.
\end{abstract}

KEY-WORDS: Oryza sativa L.; plant regulator; cytokinin.

\section{INTRODUÇÃO}

O arroz é um cereal rico em carboidratos, que faz parte da dieta diária de metade da população mundial (Kumar \& Ladha 2011). No Brasil, o abastecimento interno é proveniente, principalmente, da Região Sul, com destaque para o Estado do Rio Grande do Sul (68\%), que o cultiva sob sistema consolidado de irrigação (Conab 2015). No entanto, a disponibilidade de áreas para expansão da cultura, nessa região, é limitada, devido ao alto impacto ao

\section{RESUMO}

A utilização de reguladores vegetais em arroz pode proporcionar redução na altura de plantas e diminuir o acamamento. Objetivou-se verificar a influência da aplicação do regulador vegetal thidiazuron na cultura do arroz de terras altas, em região de Cerrado brasileiro. Utilizaram-se as cultivares BRS Esmeralda e IAC 202, bem como delineamento experimental de blocos casualizados, em esquema fatorial $4 \times 3$ para cada cultivar, constituído de doses de thidiazuron $\left(0 \mathrm{~g} \mathrm{ha}^{-1} ; 0,3 \mathrm{~g} \mathrm{ha}^{-1} ; 0,6 \mathrm{~g} \mathrm{ha}^{-1} ; \mathrm{e}\right.$ $0,9 \mathrm{~g} \mathrm{ha}^{-1}$ ) e três épocas de aplicação (perfilhamento, diferenciação floral e emborrachamento), com quatro repetições. O número de espiguetas por panícula e fertilidade das espiguetas da cultivar BRS Esmeralda foram maiores utilizando-se a dose de $0,9 \mathrm{~g} \mathrm{ha}^{-1} \mathrm{de}$ thidiazuron, com aplicação na fase de perfilhamento. A massa de 100 grãos da BRS Esmeralda se ajustou a uma equação quadrática, enquanto, para a IAC 202, houve ajuste a uma equação linear, com melhor época de aplicação durante o perfilhamento. Para massa hectolítrica da BRS Esmeralda, os resultados também se ajustaram a uma equação quadrática, enquanto, para a IAC 202, houve diferença significativa apenas entre as épocas, sendo o emborrachamento a melhor época de aplicação. As produtividades de grãos da BRS Esmeralda e IAC 202 apresentaram ajuste linear positivo, com ganhos de $23,5 \%$ e $6,5 \%$, respectivamente, em relação à testemunha. $\mathrm{O}$ thidiazuron influencia positivamente na produtividade da cultura do arroz de terras altas.

PALAVRAS-CHAVE: Oryza sativa L.; regulador vegetal; citocinina.

meio ambiente e competição pela demanda de água para uso industrial e doméstico (Heinemann \& Stone 2009).

Uma alternativa viável para o problema é a expansão da cultura do arroz de terras altas na região Centro-Oeste do Brasil, onde o arroz pode ser introduzido em áreas recém-abertas, na recuperação de pastagens degradadas e até mesmo no sistema de rotação de culturas (Kluthcouski et al. 1991, Embrapa 2006). Segundo Mendes et al. (2014), essa modalidade de cultivo está sujeita à redução da produtivi- 
dade, em consequência de veranicos ocasionais. No entanto, o arroz de terras altas cultivado com o uso de irrigação por aspersão pode proporcionar estabilidade de produção e lucratividade, estimulando o uso de práticas de maior nível tecnológico, com consequente aumento na produtividade (Arf et al. 2012). Entretanto, essas práticas podem estimular o desenvolvimento exagerado das plantas de algumas cultivares, ocasionando acamamento, o que dificulta a colheita mecanizada (Arf et al. 2012).

Dessa maneira, alguns estudos envolvendo reguladores de crescimento são realizados para a cultura do arroz, visando a diminuir a altura de plantas $\mathrm{e}$, consequentemente, o acamamento, aproveitando-se melhor a produtividade da planta. Dentre as pesquisas realizadas com reguladores vegetais encontram-se aquelas que utilizaram cloreto de mepiquat, etil-trinexapac e paclobutrazol (Nascimento et al. 2009, Arf et al. 2012, Alvarez et al. 2014), glyphosate (Gitti et al. 2011) e cloreto de clormequat (Buzetti et al. 2006). De maneira geral, os resultados desses trabalhos demonstram que o uso de subdoses desses produtos promove redução significativa na altura de plantas e reduz pouco a produtividade, mas melhora a eficiência de colheita dos grãos, visto que elimina o acamamento das plantas de arroz. Essas substâncias têm o papel de inibir a síntese do ácido giberélico nas plantas, que, por sua vez, é responsável pelo crescimento longitudinal das plantas. Esses estudos mostram que o arroz apresenta boa resposta ao uso de reguladores vegetais. Existem outros grupos de hormônios vegetais que, também, se aplicados nas doses e épocas corretas, podem proporcionar aumento na produtividade. Um exemplo são os hormônios do grupo das citocininas.

Tem sido sugerido que a citocinina estimula a mobilização de nutrientes, por estabelecer drenos fortes que são mais favorecidos na competição por nutrientes, fazendo com que haja concentração nas áreas tratadas, em função da maior vascularização nessa região (Guardiola et al. 1993, Taiz \& Zeiger 2013), bem como inibição da sua saída (Metivier 1985). O thidiazuron (N-fenil-N'-1,2,3-tiadiazol-5-ilurea), uma fenilureia do mesmo grupo do forclorfenuron, é um regulador vegetal que apresenta ação semelhante à da citocinina (Henny \& Fooshee 1991). Não existem pesquisas envolvendo o uso de thidiazuron na cultura do arroz de terras altas. Entretanto, tendo-se em vista o papel fisiológico da citocinina e a alta resposta ao uso de reguladores vegetais que o arroz apresenta, acredita-se que essa substância, se utilizada em concentrações ideais, durante determinadas fases do desenvolvimento fenológico da cultura do arroz, pode induzir aumento de produtividade.

Nesse contexto, objetivou-se verificar a influência da aplicação de três doses de thidiazuron, em diferentes estádios de desenvolvimento de dois genótipos de arroz de terras altas, nos aspectos biométricos e produtivos da cultura.

\section{MATERIAL E MÉTODOS}

O experimento foi desenvolvido no ano agrícola 2014/2015, em área experimental pertencente à Faculdade de Engenharia da Universidade Estadual Paulista "Júlio de Mesquita Filho", em Selvíria (MS) (aproximadamente $20^{\circ} 22^{\prime} \mathrm{S}$ e $51^{\circ} 22^{\prime} \mathrm{W}$, com altitude de $335 \mathrm{~m})$. O solo da área experimental é um Latossolo Vermelho distrófico típico argiloso (Santos et al. 2013), originalmente ocupado com vegetação de Cerrado. O volume de chuvas, durante a condução do experimento, totalizou $526,2 \mathrm{~mm}$, com média de temperatura máxima de $32,8{ }^{\circ} \mathrm{C}$ e temperatura mínima de $21^{\circ} \mathrm{C}$. Os dados referentes à precipitação pluviométrica e temperatura média do ar são apresentados na Figura 1.

Antes da instalação do experimento, foi realizada a caracterização química (Raij et al. 1996) do solo da área experimental, na camada de 0-0,20 m, obtendo-se os seguintes valores: $\mathrm{P}_{\text {resina }}=$ $33 \mathrm{mg} \mathrm{dm}^{-3} ; \mathrm{MO}=21 \mathrm{~g} \mathrm{dm}^{-3} ; \mathrm{K}=3,4 \mathrm{mmol}_{\mathrm{c}} \mathrm{dm}^{-3}$; $\mathrm{Ca}=20 \mathrm{mmol}_{\mathrm{c}} \mathrm{dm}^{-3} ; \mathrm{Mg}=13 \mathrm{mmol}_{\mathrm{c}} \mathrm{dm}^{-3} ; \mathrm{SB}=$ $36,4 \mathrm{mmol}_{\mathrm{c}} \mathrm{dm}^{-3} ; \mathrm{pH}=5,3 \mathrm{mmol}_{\mathrm{c}} \mathrm{dm}^{-3} ; \mathrm{Al}=0 \mathrm{mmol}_{\mathrm{c}} \mathrm{dm}^{-3}$; $\mathrm{H}+\mathrm{Al}=34 \mathrm{mmol}_{\mathrm{c}} \mathrm{dm}^{-3} ; \mathrm{S}_{-} \mathrm{SO}_{4}=2 \mathrm{mg} \mathrm{dm}^{-3} ; \mathrm{CTC}=$ $70,4 \mathrm{mmol}_{\mathrm{c}} \mathrm{dm}^{-3} ; \mathrm{V}=52 \%$.

$\mathrm{O}$ fornecimento de água foi realizado por sistema fixo de irrigação por aspersão, com precipitação média de 3,3 mm hora ${ }^{-1}$ nos aspersores. A precipitação pluvial foi determinada por meio de pluviômetro Ville de Paris, instalado nas proximidades da área experimental.

$\mathrm{O}$ delineamento experimental utilizado foi o de blocos ao acaso, em esquema fatorial 4 x 3, com quatro repetições. Os tratamentos foram constituídos por uma testemunha e três doses de thidiazuron $\left(0,3 \mathrm{~g} \mathrm{ha}^{-1} ; 0,6 \mathrm{~g} \mathrm{ha}^{-1}\right.$; e $\left.0,9 \mathrm{~g} \mathrm{ha}^{-1}\right)$, aplicadas em três estádios distintos de desenvolvimento das plantas (perfilhamento, diferenciação do primórdio da panícula e emborrachamento).

As cultivares analisadas foram a BRS Esmeralda e IAC 202, pelo fato de as plantas apresentarem 


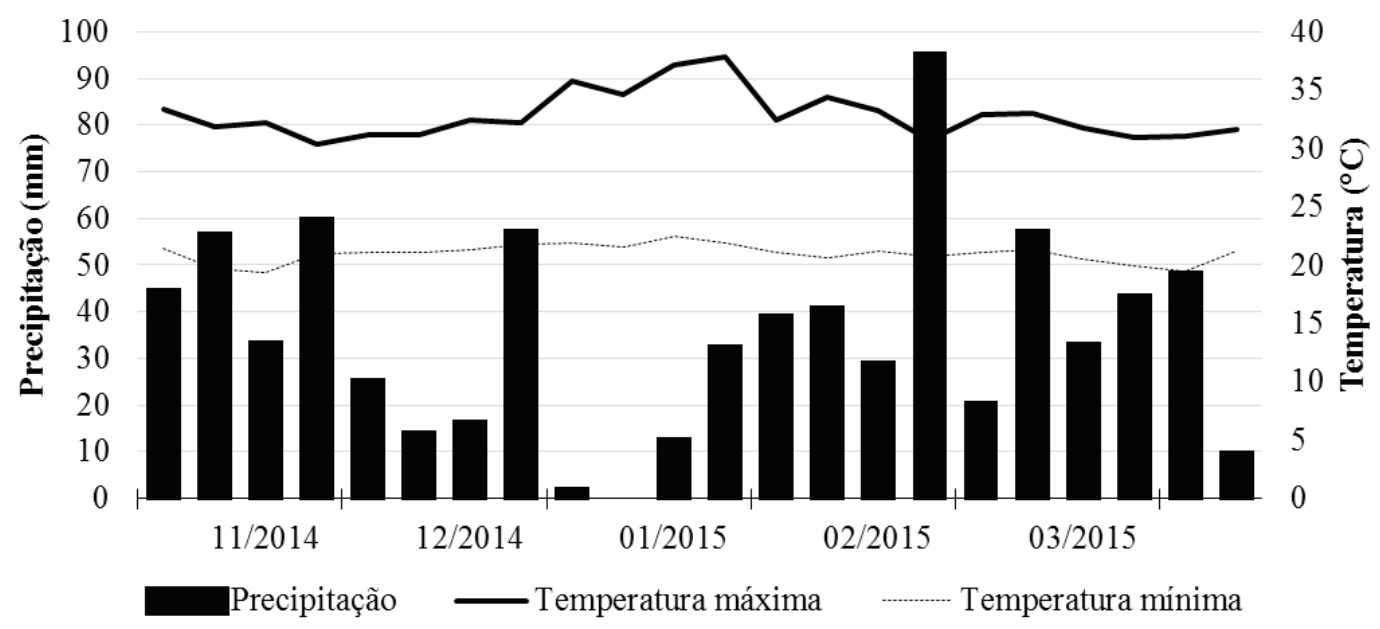

Figura 1. Dados semanais de precipitação pluviométrica e temperatura mínima e máxima do ar (Selvíria, MS, Brasil, 2014/2015).

características pertencentes ao grupo intermediário e moderno, respectivamente. O grupo moderno caracteriza-se por apresentar plantas de porte baixo, folhas curtas e eretas, colmos fortes, elevado perfilhamento e responder em produtividade de grãos, quando submetidas a altos níveis de tecnologia, como adubação, sem acamar. Já no grupo intermediário, as plantas apresentam porte médio e são mais suscetíveis ao acamamento (Santos et al. 2006). As parcelas foram constituídas por cinco linhas de $5,0 \mathrm{~m}$ de comprimento, espaçadas $0,35 \mathrm{~m}$ entre si, e a área útil por três linhas centrais de cada parcela.

As aplicações do regulador vegetal thidiazuron foram realizadas na forma de jato dirigido, com pulverizador manual tipo costal (volume de calda de $200 \mathrm{~L} \mathrm{ha}^{-1}$ ), no período da manhã (entre 8:00 h e 9:00 h), com umidade relativa próxima a $90 \%$ e velocidade do vento de $0-1,0 \mathrm{~m} \mathrm{~s}^{-1}$, e solo apresentando umidade próxima à capacidade de campo.

O preparo do solo da área foi o convencional, utilizando-se uma gradagem pesada e uma leve, imediatamente antes da semeadura, a qual foi realizada no dia 15 de novembro de 2014, utilizando-se espaçamento de $0,35 \mathrm{~m}$ entre as linhas e 280 sementes $\mathrm{m}^{-2}$. O tratamento de sementes foi realizado com fipronil (50 g do i.a. $100 \mathrm{~kg}^{-1}$ de sementes). A adubação utilizada na semeadura forneceu $16 \mathrm{~kg} \mathrm{ha}^{-1} \mathrm{de} \mathrm{N}, 56 \mathrm{~kg} \mathrm{ha}^{-1}$ de $\mathrm{P}_{2} \mathrm{O}_{5}$ e $32 \mathrm{~kg} \mathrm{ha}^{-1}$ de $\mathrm{K}_{2} \mathrm{O}$, por meio da aplicação de $200 \mathrm{~kg} \mathrm{ha}^{-1}$ do adubo na formulação 08-28-16.

O controle de plantas daninhas foi efetuado com a utilização de herbicidas pré e pós-emergentes, sendo o pendimetalin (1.400 $\mathrm{g}_{\text {do i.a. }} \mathrm{ha}^{-1}$ ) aplicado logo após a semeadura, metsulfurom metil $(1,8 \mathrm{~g}$ do i.a. ha-1) aos 19 dias após a emergência (DAE) das plantas e 2,4-D (960 g do i.a. ha-1) aos 36 DAE.

A adubação nitrogenada em cobertura foi parcelada. Aplicou-se a primeira parcela aos 23 DAE, com $40 \mathrm{~kg} \mathrm{ha}^{-1}$ de $\mathrm{N}$, e a segunda aos $38 \mathrm{DAE}$, com $30 \mathrm{~kg} \mathrm{ha}^{-1}$ de N, ambas utilizando-se, como fonte, o sulfato de amônio.

Durante o período de condução do experimento e em pós-colheita, foram realizadas as seguintes avaliações: altura de plantas - média das distâncias da superfície do solo até a extremidade superior da panícula mais alta, determinada em dez plantas ao acaso; acamamento de plantas - obtido por observações visuais, na fase de maturação, utilizando-se a seguinte escala de notas: 0 - sem acamamento; 1 - até $5 \%$ de plantas acamadas; 2 - 5-25\%; 3 - 25-50\%; 4 - 50-75\%; e 5 - 75-100\%; número de panículas por metro quadrado - contagem das panículas em 1,0 m de fileira de plantas, posteriormente convertido em panículas por metro quadrado; número de espiguetas por panícula - contagem dos grãos de 20 panículas, coletadas no momento da colheita; fertilidade das espiguetas - relação entre o número de grãos cheios e chochos por panícula, após a separação dos mesmos por fluxo de ar, obtidos com as amostras utilizadas para a determinação do número de espiguetas por panícula; massa de cem grãos - média da massa de duas amostras de cem grãos; massa hectolitrica determinada em balança especial para massa hectolítrica, utilizando-se duas amostras; produtividade de grãos - massa dos grãos provenientes da área útil, extrapolada para $\mathrm{kg} \mathrm{ha}^{-1}$. Os valores das massas foram corrigidos para umidade de $13 \%$ (base úmida). 
Os dados foram submetidos à análise de variância e, posteriormente, à análise de regressão polinomial, para o fator quantitativo (doses do regulador de crescimento), e teste Tukey, para o fator qualitativo (épocas de aplicação).

\section{RESULTADOS E DISCUSSÃO}

Os resultados obtidos referentes à altura de plantas, panículas por $\mathrm{m}^{2}$ e nota de acamamento não apresentaram diferenças estatísticas, em função de épocas ou doses de aplicação de thidiazuron (Tabela 1). Verifica-se que apenas a cultivar BRS Esmeralda apresentou acamamento, sendo esta uma característica das cultivares pertencentes ao grupo intermediário, no qual elevados níveis de tecnologia, como adubação, podem favorecer o acamamento das plantas. Arf et al. (2012) relatam que a cultivar IAC 202 dispensa o uso de reguladores de crescimento, por não apresentar acamamento.

O thidiazuron não reduziu a altura de plantas, pois trata-se de um regulador vegetal com efeito citocinínico. A maioria dos reguladores vegetais utilizados na cultura do arroz tem por objetivo reduzir a altura de plantas e apresenta efeito inibidor da síntese do ácido giberélico.

Dario et al. (2004), trabalhando com um fitorregulador à base de citocinina, auxina e giberelina, aplicado em diferentes épocas, em cultivar de arroz conduzida sob sistema de irrigação por inundação, também não obtiveram diferença significativa para as variáveis altura de plantas e número de panículas por $\mathrm{m}^{2}$.

Em relação ao número de espiguetas por panícula, observa-se que a cultivar BRS Esmeralda apresentou diferença, em função dos tratamentos (Tabela 2). A melhor época de aplicação foi durante a fase de perfilhamento, sendo que as doses aplicadas se ajustaram a uma equação de crescimento linear, em que a dose de $0,9 \mathrm{~g} \mathrm{ha}^{-1}$ gerou $13,4 \%$ mais espiguetas por panícula, em comparação ao tratamento testemunha.

Segundo Buzetti et al. (2006), o número de espiguetas por panícula é influenciado por fatores genéticos e condições externas vigentes durante a fase reprodutiva, mais precisamente do início da fase reprodutiva até os cinco dias que antecedem o florescimento. No presente trabalho, verificou-se que a melhor época de aplicação foi antes do início da fase reprodutiva. Sendo assim, pode-se inferir que o número de espiguetas por panícula pode ser influenciado por estímulos que antecedem a fase de diferenciação floral, na BRS Esmeralda.

Para fertilidade das espiguetas, nota-se que a BRS Esmeralda foi influenciada pelas épocas de aplicação, sendo os melhores resultados obtidos com aplicações realizadas na fase de perfilhamento e diferenciação floral (Tabela 2). As doses de aplicação não foram significativas para a BRS Esmeralda. Já a cultivar IAC 202 apresentou ajuste linear de crescimento

Tabela 1. Média de altura de plantas, panículas por $\mathrm{m}^{2}$ e nota de acamamento das cultivares BRS Esmeralda e IAC 202, em função de doses e épocas de aplicação de thidiazuron (Selvíria, MS, Brasil, 2014/2015).

\begin{tabular}{|c|c|c|c|c|c|c|}
\hline Tratamentos & \multicolumn{2}{|c|}{ Altura de plantas $(\mathrm{cm})$} & \multicolumn{2}{|c|}{ Panículas por $\mathrm{m}^{2}$} & \multicolumn{2}{|c|}{ Notas de acamamento $^{(1)}$} \\
\hline Épocas $(\mathrm{E})$ & BRS Esmeralda & IAC 202 & BRS Esmeralda & IAC 202 & BRS Esmeralda ${ }^{(2)}$ & IAC 202 \\
\hline Perfilhamento & 112 & 99 & 324 & 305 & 2,5 & 0 \\
\hline Diferenciação floral & 113 & 101 & 312 & 294 & 2,0 & 0 \\
\hline Emborrachamento & 114 & 98 & 314 & 295 & 2,8 & 0 \\
\hline \multicolumn{7}{|l|}{ Doses (D) } \\
\hline 0 & 112 & 99 & 312 & 286 & 2,8 & 0 \\
\hline 0,3 & 112 & 100 & 325 & 298 & 2,3 & 0 \\
\hline 0,6 & 113 & 98 & 307 & 309 & 2,9 & 0 \\
\hline 0,9 & 114 & 99 & 324 & 300 & 1,9 & 0 \\
\hline \multicolumn{7}{|l|}{ Teste F } \\
\hline Épocas & $1,01^{\mathrm{ns}}$ & $0,83^{\mathrm{ns}}$ & $0,34^{\mathrm{ns}}$ & $0,53^{\mathrm{ns}}$ & $1,28^{\mathrm{ns}}$ & - \\
\hline Doses & $0,38^{\mathrm{ns}}$ & $0,23^{\text {ns }}$ & $0,51^{\mathrm{ns}}$ & $1,00^{\mathrm{ns}}$ & $0,86^{\mathrm{ns}}$ & - \\
\hline $\mathrm{E} \times \mathrm{D}$ & $2,16^{\mathrm{ns}}$ & $0,43^{\text {ns }}$ & $1,08^{\mathrm{ns}}$ & $0,40^{\text {ns }}$ & $2,42^{\mathrm{ns}}$ & - \\
\hline D.M.S (5\%) & 3,62 & 5,97 & 36,97 & 28,74 & 0,44 & - \\
\hline CV (\%) & 3,69 & 6,91 & 13,43 & 11,10 & 31,77 & - \\
\hline
\end{tabular}

(1) 0 - sem acamamento; 1 - até $5 \%$ de plantas acamadas; 2 - 5-25\%; 3 - 25-50 \%; 4 - 50-75\%; e 5 - 75-100 \%. (2) Para a análise estatística, os dados foram transformados em raiz quadrada de $(x+0,5)$. Médias seguidas de letras diferentes, nas colunas, diferem estatisticamente entre si pelo teste Tukey, a $5 \%$. ${ }^{n s}$ não significativo. 
Tabela 2. Média de espiguetas por panícula e fertilidade das espiguetas das cultivares BRS Esmeralda e IAC 202, em função de doses e épocas de aplicação de thidiazuron (Selvíria, MS, Brasil, 2014/2015).

\begin{tabular}{|c|c|c|c|c|}
\hline Tratamentos & \multicolumn{2}{|c|}{ Espiguetas por panícula } & \multicolumn{2}{|c|}{ Fertilidade das espiguetas (\%) } \\
\hline Épocas (E) & BRS Esmeralda & IAC 202 & BRS Esmeralda & IAC 202 \\
\hline Perfilhamento & $149 \mathrm{a}$ & 202 & $87,0 \mathrm{a}$ & 85,1 \\
\hline Diferenciação floral & $131 \mathrm{~b}$ & 208 & $86,5 \mathrm{ab}$ & 84,4 \\
\hline Emborrachamento & $138 \mathrm{~b}$ & 201 & $82,0 \mathrm{~b}$ & 84,9 \\
\hline \multicolumn{5}{|l|}{ Doses (D) } \\
\hline 0 & $131^{(1)}$ & 211 & 83,4 & $82,4^{(2)}$ \\
\hline 0,3 & 135 & 205 & 86,1 & 83,3 \\
\hline 0,6 & 139 & 195 & 84,4 & 86,4 \\
\hline 0,9 & 149 & 202 & 86,8 & 87,2 \\
\hline \multicolumn{5}{|l|}{ Teste $\mathrm{F}$} \\
\hline Épocas & $3,53^{*}$ & $1,06^{\text {ns }}$ & $3,52^{*}$ & $0,24^{\text {ns }}$ \\
\hline Doses & $7,13 * *$ & $2,63^{\text {ns }}$ & $0,85^{\mathrm{ns}}$ & $7,46^{* *}$ \\
\hline$E \times D$ & $2,04^{\mathrm{ns}}$ & $1,91^{\mathrm{ns}}$ & $1,57^{\mathrm{ns}}$ & $1,05^{\text {ns }}$ \\
\hline D.M.S (5 \%) & 8,58 & 12,40 & 4,96 & 2,59 \\
\hline CV (\%) & 7,12 & 7,05 & 6,88 & 3,53 \\
\hline
\end{tabular}

da fertilidade das espiguetas, em função das doses aplicadas, demonstrando aumento de 5,8 \%, com a dose de $0,9 \mathrm{~g} \mathrm{ha}^{-1}$. Por outro lado, Alvarez et al. (2012) verificaram redução na fertilidade das espiguetas, quando aplicaram paclobutrazol e etil-trinexapac, em relação ao tratamento controle, por ocasião da diferenciação da panícula. Já Buzetti et al. (2006) relatam que o regulador cloreto de clormequat não influenciou na fertilidade das espiguetas, enquanto doses de nitrogênio reduziram este componente na cultivar IAC 202.

$\mathrm{O}$ aspecto fertilidade das espiguetas influencia diretamente na produtividade de grãos (Evans \& Bhatt 1977), pois expressa a porcentagem de espiguetas que se tornarão grãos (Buzetti et al. 2006). Ainda segundo os mesmos autores, esse componente produtivo é dependente da translocação de carboidratos e influenciado pelo ambiente, assim como pelos fertilizantes nitrogenados. Pelos resultados obtidos, pode-se afirmar que, pelo menos em alguns genótipos, como na cultivar IAC 202, o thidiazuron, possivelmente, aumenta a translocação de carboidratos para a panícula, fazendo com que isso reflita em maior fertilidade das espiguetas.

Para o aspecto massa de 100 grãos, os resultados da cultivar BRS Esmeralda apresentaram ajuste à regressão quadrática, com a maior dose de thidiazuron encontrada sendo de $0,48 \mathrm{~g} \mathrm{ha}^{-1}$, atingindo valores de 2,98 g (Tabela 3). A massa de 100 grãos da IAC 202 também foi influenciada pela aplicação de thidiazuron, de modo que as melhores épocas de aplicação foram o perfilhamento e diferenciação floral, e as doses se ajustaram a uma regressão linear positiva, com aumento de até $3,2 \%$, em relação à testemunha, utilizando-se a dose de $0,9 \mathrm{~g} \mathrm{ha}^{-1}$ (Tabela 3). Possivelmente, esses resultados aconteceram devido ao maior carreamento de fotoassimilados para os grãos, proporcionado pelo efeito citocinínico do thidiazuron.

Em relação à massa hectolítrica (Tabela 3), a cultivar IAC 202 apresentou maiores resultados quando o thidiazuron foi aplicado por ocasião do emborrachamento, não sendo influenciada pelas doses aplicadas. Já a BRS Esmeralda foi influenciada apenas pelas doses de thidiazuron, de modo que os resultados se ajustaram à equação de regressão quadrática, em que as maiores médias foram obtidas no tratamento testemunha.

Vale ressaltar que, mesmo durante o ponto ideal de colheita da cultivar BRS Esmeralda, havia grãos com textura leitosa. Isso, possivelmente, resultou na redução da massa hectolítrica, pois esse componente é convertido a $13 \%$ de umidade na base úmida, sugerindo que o thidiazuron retarda o ponto de maturidade da planta. Esse fato foi comprovado por Metivier (1985), que afirmou que aplicações de citocininas sintéticas podem ocasionar atraso no amadurecimento, por retardarem a senescência de frutos.

No que diz respeito à produtividade, ambas as cultivares apresentaram ajuste de crescimento linear, 
Tabela 3. Média de massa de 100 grãos, massa hectolítrica e produtividade de grãos das cultivares BRS Esmeralda e IAC 202, em função de doses e épocas de aplicação de thidiazuron (Selvíria, MS, Brasil, 2014/2015).

\begin{tabular}{|c|c|c|c|c|c|c|}
\hline \multirow{2}{*}{$\begin{array}{c}\text { Tratamentos } \\
\text { Épocas }(\mathrm{E})\end{array}$} & \multicolumn{2}{|c|}{ Massa de 100 grãos (g) } & \multicolumn{2}{|c|}{ Massa hectolítrica $(\mathrm{kg})$} & \multicolumn{2}{|c|}{ Produtividade de grãos $\left(\mathrm{kg} \mathrm{ha}^{-1}\right)$} \\
\hline & BRS Esmeralda & IAC 202 & BRS Esmeralda & IAC 202 & BRS Esmeralda & IAC 202 \\
\hline Perfilhamento & 2,94 & $2,21 \mathrm{a}$ & 53,7 & $50,8 \mathrm{~b}$ & 6.397 & 5.612 \\
\hline Diferenciação floral & 2,94 & $2,21 \mathrm{a}$ & 52,5 & $51,1 \mathrm{~b}$ & 6.004 & 5.640 \\
\hline Emborrachamento & 2,89 & $2,17 \mathrm{~b}$ & 51,6 & $52,1 \mathrm{a}$ & 5.933 & 5.786 \\
\hline \multicolumn{7}{|l|}{ Doses (D) } \\
\hline 0 & $2,85^{(1)}$ & $2,16^{(2)}$ & $55,2^{(3)}$ & 51,6 & $5.464^{(4)}$ & $5.431^{(5)}$ \\
\hline 0,3 & 2,99 & 2,18 & 52,5 & 51,4 & 5.907 & 5.525 \\
\hline 0,6 & 2,95 & 2,23 & 51,9 & 51,3 & 6.325 & 5.976 \\
\hline 0,9 & 2,90 & 2,23 & 52,5 & 51,1 & 6.749 & 5.786 \\
\hline \multicolumn{7}{|l|}{ Teste F } \\
\hline Épocas & $1,43^{\mathrm{ns}}$ & $7,81 * *$ & $2,20^{\mathrm{ns}}$ & $7,01 * *$ & $1,52^{\mathrm{ns}}$ & $0,68^{\text {ns }}$ \\
\hline Doses & $4,80 * *$ & $15,39 * *$ & $11,82 * *$ & $0,49^{\text {ns }}$ & $5,59 * *$ & $3,65^{*}$ \\
\hline $\mathrm{E} \times \mathrm{D}$ & $0,99^{\mathrm{ns}}$ & $0,66^{\mathrm{ns}}$ & $1,14^{\mathrm{ns}}$ & $0,63^{\mathrm{ns}}$ & $0,93^{\mathrm{ns}}$ & $3,07^{\mathrm{ns}}$ \\
\hline D.M.S $(5 \%)$ & 0,08 & 0,02 & 1,30 & 0,90 & 700 & 390 \\
\hline CV (\%) & 3,27 & 1,37 & 2,83 & 2,03 & 13,21 & 7,92 \\
\hline
\end{tabular}

em função das doses de thidiazuron (Tabela 3). A dose de $0,9 \mathrm{~g} \mathrm{ha}^{-1}$ proporcionou à cultivar BRS Esmeralda produtividade de $6.749 \mathrm{~kg} \mathrm{ha}^{-1}, 23,5 \%$ a mais que a testemunha. Na IAC 202, a mesma dose propiciou produtividade de $5.786 \mathrm{~kg} \mathrm{ha}^{-1}, 6,5 \%$ superior à testemunha. Esse resultado pode ser explicado pelos aumentos em alguns componentes, como número de espiguetas por panícula e fertilidade das espiguetas, que, possivelmente, refletiram na produtividade.

Resultados semelhantes foram encontrados por Dario et al. (2004), quando utilizaram um biorregulador contendo auxina, citocinina e giberelina, aos 43 dias após a emergência. Os autores observaram $14,3 \%$ de aumento, em relação à testemunha, na cultivar IAC 103, sob condição irrigada.

Arf et al. (2012) verificaram aumento na produtividade da BRS Primavera e Caiapó, enquanto a cultivar IAC 202 apresentou redução, em função do incremento de doses do regulador etil-trinexapac, divergindo dos resultados encontrados neste trabalho. Vale ressaltar que, para a BRS Primavera e Caiapó, pertencentes ao grupo intermediário e com porte médio, o aumento na produtividade se deu pelo melhor aproveitamento de plantas, com redução no acamamento, diferindo do thidiazuron, que potencializou a produtividade, independentemente do acamamento das plantas. Alvarez et al. (2007 e 2014) e Nascimento et al. (2009) também relataram efeito de redução na produtividade de grãos, na cultura do arroz, causada pela aplicação de etil-trinexapac.

Em nossa pesquisa, o thidiazuron causou efetivo aumento da produtividade, em duas cultivares de arroz de terras altas. Sendo assim, pode-se inferir que o thidiazuron é um regulador com grande potencial para essa cultura.

\section{CONCLUSÕES}

1. A utilização de thidiazuron não influencia na altura de plantas das cultivares BRS Esmeralda e IAC 202.

2. A aplicação de thidiazuron na fase de perfilhamento proporciona aumento significativo nos componentes produtivos das cultivares BRS Esmeralda e IAC 202.

3. A dose de $0,9 \mathrm{~g} \mathrm{ha}^{-1}$ de thidiazuron proporciona as maiores produtividades de grãos, para as cultivares BRS Esmeralda e IAC 202.

\section{REFERÊNCIAS}

ALVAREZ, R. C. F.; CRUSCIOL, C. A. C.; NASCENTE, A. S. Produtividade de arroz de terras altas em função de reguladores de crescimento. Revista Ceres, Viçosa, v. 61, n. 1, p. 42-49, 2014.

ALVAREZ, R. C. F. et al. Gas exchange rates, plant height, yield components, and productivity of upland rice 
as affected by plant regulators. Pesquisa Agropecuária Brasileira, Brasília, DF, v. 47, n. 10, p. 1455-1461, 2012.

ALVAREZ, R. C. F. et al. Aplicação de reguladores vegetais na cultura de arroz de terras altas. Acta Scientiarum Agronomy, Maringá, v. 29, n. 2, p. 241-249, 2007.

ARF, O. et al. Uso de etil-trinexapac em cultivares de arroz de terras altas. Pesquisa Agropecuária Tropical, Goiânia, v. 42, n. 2, p. 150-158, 2012.

BUZETTI, S. et al. Resposta de cultivares de arroz a doses de nitrogênio e do regulador de crescimento cloreto de clormequat. Pesquisa Agropecuária Brasileira, Brasília, DF, v. 41, n. 12, p. 1731-1737, 2006.

COMPANHIA NACIONAL DE ABASTECIMENTO (Conab). Acompanhamento da safra brasileira de grãos: safra 2014/15.2015. Disponível em: <http://www.conab.gov. br/OlalaCMS/uploads/arquivos/15_05_13_08_46_55 boletim_graos_maio_2015.pdf $>$. Acesso em: 22 jun. $201 \overline{5}$.

DARIO, G. J. A. et al. Influência do uso de fitorregulador no crescimento do arroz irrigado. Revista da FZVA, Uruguaiana, v. 11, n. 1, p. 86-94, 2004.

EMPRESA BRASILEIRA DE PESQUISA AGROPECUÁRIA (Embrapa). Cultivo do arroz de terras altas no Estado de Mato Grosso. Santo Antônio de Goiás: Embrapa Arroz e Feijão, 2006.

EVANS, L. E.; BHATT, G. M. Influence of seed size, protein content and cultivar on early seedling vigor in rice. Canadian Journal of Plant Science, Otawa, v. 57, n. 7, p. 929-935, 1977.

GITTI, D. C. et al. Glyphosate como regulador de crescimento em arroz de terras altas. Pesquisa Agropecuária Tropical, Goiânia, v. 41, n. 4, p. 500-507, 2011.

GUARDIOLA, J. L. et al. Effects of exogenous growth regulators on fruit development in Citrus unshiu. Annals of Botany, London, v. 71, n. 2, p. 169-172, 1993.
HEINEMANN, A. B.; STONE, L. F. Efeito da deficiência hídrica no desenvolvimento e rendimento de quatro cultivares de arroz de terras altas. Pesquisa Agropecuária Tropical, Goiânia, v. 39, n. 2, p. 134-139, 2009.

HENNY, R. J.; FOOSHEE, W. C. Treatment of syngonium 'Maya Red' with thidiazuron in attempt to induce basal branching. Apopka: University of Florida, 1991.

KLUTHCOUSKI, J. et al. Renovação de pastagens de Cerrado com arroz: 1. Sistema Barreirão. Goiânia: Embrapa-CNPAF, 1991. (Documentos, 33).

KUMAR, V.; LADHA, J. K. Direct seeding of rice: recent developments and future research needs. Advances in Agronomy, San Diego, v. 111, n. 1, p. 297-413, 2011.

MENDES, C. A. et al. Análise de associação quanto à produtividade e seus caracteres componentes em linhagens e cultivares de arroz de terras altas. Pesquisa Agropecuária Brasileira, Brasília, DF, v. 49, n. 10, p. 771-782, 2014.

METIVIER, J. R. Giberelinas. In: FERRI, M. G. Fisiologia vegetal. 2. ed. São Paulo: EPU, 1985. p. 93-128.

NASCIMENTO, V. et al. Uso do regulador de crescimento etil-trinexapac em arroz de terras altas. Bragantia, Campinas, v. 68, n. 4, p. 921-929, 2009.

RAIJ, B. V. et al. Recomendações de adubação e calagem para o Estado de São Paulo. 2. ed. Campinas: IAC, 1996. (Boletim técnico, 100).

SANTOS, A. B.; STONE, L. F.; VIEIRA, N. R. A. $A$ cultura do arroz no Brasil. 2. ed. Santo Antônio de Goiás: Embrapa Arroz e Feijão, 2006.

SANTOS, H. G. et al. Sistema brasileiro de classificação de solos. 3. ed. Brasília, DF: Embrapa, 2013.

TAIZ, L.; ZEIGER, E. Fisiologia vegetal. 5. ed. Porto Alegre: Artmed, 2013. 